\title{
ANALISIS PENGOPERASIAN REAKTOR RSG-GAS PADA TERAS 96 DENGAN DAYA MAKSIMUM $30 \mathrm{MW}$.
}

\section{ANALYSIS OF OPERATING THE RSG-GAS REACTOR ON THE CORE 96 WITH A MAXIMUM POWER OF $30 \mathrm{MW}$}

\author{
${ }^{1}$ Sukiyanto, ${ }^{2}$ Susanto, ${ }^{3}$ Bagus Dwi Nurtanto \\ ${ }^{1.2 .3}$ PRSG-BATAN, Kawasan Puspiptek Gd.30, Serpong, 15310 \\ e-mail : sukiyanto@batan.go.id
}

Diterima: 8 Oktober 2018, diperbaiki : 12 Oktober 2018, disetujui : 15 Oktober 2018

\begin{abstract}
ABSTRAK
ANALISIS PENGOPERASIAN REAKTOR RSG-GAS PADA TERAS 96 DENGAN DAYA MAKSIMUM 30 MW. Reaktor RSG-GAS merupakan reaktor riset dengan daya nominal $30 \mathrm{MW}$ termal yang digunakan untuk kegiatan penelitian, iradiasi, pendidikan dan pelatihan.Reaktor RSG-GAS dioperasikan rutin hanya pada daya $15 \mathrm{MW}$, sedangkan operasi reaktor dengan daya maksimum $30 \mathrm{MW}$ dilakukan dalam waktu tertentu sesuai permintaan dan persetujuan dari BAPETEN (sebagai badan pengawas). Pengoperasian reaktor RSG-GAS pada teras 92 dengan daya maksimum $30 \mathrm{MW}$ ada perbedaan/ ketidaksesuaian antara daya yang dikehendaki (30 MW) dengan daya aktual (28,008 MW). Pengoperasian reaktor RSG-GAS pada teras 96 dengan daya 30 MW dilakukan kalibrasi daya reaktor kemudian hasilnya dibandingkan dengan daya yang dikehendaki. Hasil kalibrasi daya reaktor untuk pengoperasian daya $30 \mathrm{MW}$ adalah sebesar 30,040 MW. Hasil perbandingan antara daya aktual / hasil kalibrasi dengan daya yang dikehendaki hampir sama. Hal tersebut menunjukan terjadi kesesuaian pengoperasian reaktor RSG-GAS pada teras 96 dengan daya maksimum 30 MW.
\end{abstract}

Kata kunci : Reaktor RSG-GAS, Operasi Reaktor, Kalibrasi Daya, .

\section{ABSTRACT}

ANALYSIS OF OPERATING THE RSG-GAS REACTOR ON THE CORE 96 WITH A MAXIMUM POWER OF 30 MW. The RSG-GAS reactor is a research reactor with a nominal power of $30 \mathrm{MW}$ thermal that is used for research, irradiation, education and training activities. The RSG-GAS reactor is operated routinely only at $15 \mathrm{MW}$ of power, while reactor is in operation with a maximum power of $30 \mathrm{MW}$ carried out within a certain time on request and approval from BAPETEN (as the regulatory body). In the RSG-GAS reactor operation of the core 92 with a maximum power of $30 \mathrm{MW}$ therewas a difference / discrepancy between the desired power $(30 \mathrm{MW})$ and the actual power $(28,008 \mathrm{MW})^{[13]}$. In the RSG-GAS reactor operation of the core 96 with a power of $30 \mathrm{MW}$ the reactor power calibration was carried out then the results compared with the desired power. The results of the reactor power calibration for the operation of $30 \mathrm{MW}$ of power is 30,040 MW. The results of the comparison between the actual power / calibration results with the desired power is almost the same. This shows that there is a suitability for the operation of the RSG-GAS reactor on core 96 with a maximum power of $30 \mathrm{MW}$.

Keywords : RSG-GAS Reactor, Reactor Operation, Power Calibration. 


\section{PENDAHULUAN}

R eaktor Serba Guna G.A Siwabessy (RSG-GAS) merupakan reaktor riset jenis MTR (Material Testing Reaktor) pertama di dunia yang dioperasikan langsung dengan menggunakan elemen bakar pengkayaan Uranium rendah, LEU (Low Enriched Uranium). Reaktor RSG-GAS digunakan untuk kegiatan penelitian, iradiasi dan pendidikan serta pelatihan.Dengan daya nominal $30 \mathrm{MW}$ termal reaktor RSG-GAS didesain berupa kolam terbuka dengan air sebagai pendingin sekaligus moderator serta Beryllium sebagai reflektor.Sesuai dengan kondisi yang ada dan beberapa pertimbangan maka reaktor RSG-GAS dioperasikan rutin hanyapada daya $15 \mathrm{MW}$ termal. Untuk memastikan

dan menjamin komponen dan sistem keselamatan reaktor RSG-GAS dalam kondisi baik dan aman dalam waktu tertentureaktor RSG-GAS dioperasikan pada daya nominal 30 MW sesuai permintaan Badan Pengawas Tenaga Nuklir (BAPETEN). Sedangkan untuk menjamin keandalan dan kebenaran penunjukan kanal pengukuran daya reaktor, maka harus selalu dilakukan kalibrasi secara periodik, yaitu menyesuaikan atau mengatur ulang alat ukur atau kanal - kanal ukur terhadap besaran atau nilai standar yang telah diketahui, terutama setelah dilakukan perubahan konfigurasi teras reaktor.

\section{Operasi reaktor RSG-GAS} dengan daya $30 \mathrm{MW}$ pada teras 92 terjadi ketidaksesuaian atau perbedaan antara daya yang dikehendaki (30 MW) dengan daya sebenarnya / aktual / hasil kalibrasi $(28,008 \mathrm{MW}){ }^{[1]}$. Hal tersebut menimbulkan keragu - raguan apakah reaktor sudah benar - benar dioperasikan pada daya nominal yang dikehendaki atau belum. Ketidaksesuaian daya dalam operasi reaktor terutama pada daya nominal (maksimum) seperti diatas dapat mengarah pada operasi yang tidak aman (reaktor scram) atau bahkan kecelakaan jika daya sesungguhnya melewati batas keselamatan operasi (34,2 MW).

Pada teras 96 reaktor RSG-GAS selain dioperasikan secara rutin pada daya $15 \mathrm{MW}$ juga dilakukan operasi pada daya maksimum $30 \mathrm{MW}$.

Pada makalah ini dilakukan kalibrasi daya reaktor dan kemudian membandingkan daya yang dikehendaki dengan daya hasil kalibrasi pada pengoperasian reaktor RSG-GAS teras 96 dengan daya maksimum $30 \mathrm{MW}$. Tujuan dilakukan kalibrasi daya reaktor dan membandingkan daya yang dikehendaki dengan daya hasil kalibrasi ini untuk memastikan kesesuaian pengoperasian reaktor RSG-GAS pada teras 96 dengan daya maksimum 30 MW.

\section{OPERASI REAKTOR RSG-GAS}

Kegiatan pengoperasian reaktor RSG-GAS yang dilakukan adalah operasi moda 1 (Operasi Daya) yaitu operasi reaktor dimulai dari awal (start-up) sampai ke operasi daya (power operation) pada daya lebih dari $3 \%$ daya penuh ${ }^{[2]}$.

Sebelum reaktor RSG-GAS dioperasikan maka syarat teknis dan administratif harus telah dipenuhi, diantaranya ada ijin dari Ka. PRSG dan perintah untuk mengoperasikan reaktor dari Ka. Bidang Operasi Reaktor yang tertuang dalam Instruksi Operasi (IO). Tersedia Persiapan Sarana Operasi (PSO) yang telah dilakukan dan dinyatakan bahwa reaktor boleh dioperasikan.

Teras / kolam reaktor kondisi aman, sekat apung telah dipasang, pendingin utama telah dioperasikan, rekorder dan FFD telah dioperasikan dan telah dilakukan test scram merupakan 
kondisi awal yang harus dipenuhi atau dilakukan sebelum reaktor dioperasikan.

Selanjutnya memastikan slstemsistem pendukung operasi reaktor yaitu sistem pendukung yang selalu beroperasi baik pada saat reaktorpadam maupun beroperasi dan juga sistem yang hanya beroperasi pada saat reaktor beroperasi dalam kondisi normal, sehingga kegiatan operasi reaktor dapat dilaksanakan dengan baik, aman dan selamat.

Setelah semua hal di atas dilaksanakan maka pengoperasian reaktor dapat dilakukan dengan memperhatikan batasan - batasan dalam pengoperasian di meja kendali.

Dengan mematuhi persyaratan baik teknis maupun administratif serta melaksanakan SOP yang ada dengan sebaik - baiknya diharapkan reaktor RSG-GAS dapat dioperasikan dengan aman dan selamat dari awal hingga selesai.

\section{KALIBRASI DAYA REAKTOR}

Kalibrasi daya reaktor meliputi seluruh kegiatan pengukuran parameter variabel daya, kalkulasi daya reaktor dan pengaturan ulang instrument / kanal ukur daya. Kalibrasi daya reaktor bertujuan untuk mengetahui daya reaktor yang sebenarnya juga untuk menyesuaikan meter - meter daya sesuai dengan hasil kalibrasi.

Kalibrasi daya reaktor dapat dilakukan dalam dua cara, kalibrasi secara nuklir dan secara kalorimetri (termo). Kalibrasi daya secara nuklir biasanya hanya dilakukan untuk reaktor reaktor dengan daya rendah, karena kalibrasi ini dilakukan dengan mengukur fluks neutron secara langsung pada masing - masing elemen bakar, dan pengukuran fluks neutron itu sendiri hanya bisa dilakukan pada operasi daya rendah.
Kalibrasi secara kalorimetri (termo) ada dua macam yaitu nonstasioner dan stasioner. Kalibrasi daya reaktor kalorimetri non-stasioner dilakukan dengan mengukur kenaikan suhu air kolam reaktor tanpa mengoperasikan sistem pendingin reaktor. Kalibrasi daya ini juga hanya digunakan untuk reaktor dengan daya rendah, karena pada operasi reaktor daya tinggi sistem pendingin reaktor harus dalam kondisi dioperasikan.

Kalibrasi daya reaktor kalorimetri stasioner cocok digunakan untuk reaktor dengan daya tinggi, yaitu dengan mengoperasikan sistem pendingin reaktor dan mengukur suhu air keluaran dan masukan teras reaktor, kemudian dikonversikan sebagai daya standar.

Suatu reaktor yang beroperasi pada daya tetap didinginkan oleh fluida pendingin dengan laju alir tetap, maka perbedaan suhu pendingin keluaran dan masukan teras reaktor menyatakan jumlah panas yang dipindahkan dari teras ke pendingin. Kalibrasi daya dengan metode kalorimetri pada prinsipnya berdasarkan pada pengukuran kenaikan suhu air pendingin yang diakibatkan oleh panas hasil fisi pada teras reaktor yang dipindahkan ke air pendingin. Besarnya kenaikan suhu bergantung kepada besarnya panas pada teras reaktor, massa aliran pendingin dan panas spesifik. Besarnya daya reaktor dapat dihitung dengan Persamaan (1) atau (2) ${ }^{[3]}$ :

$$
\begin{aligned}
& \mathrm{Q}=\mathrm{m} \cdot \mathrm{Cp} \cdot\left(\mathrm{T}_{\text {in }}-\mathrm{T}_{\text {out }}\right) \\
& \text { atau } \\
& \mathrm{Q}=\mathrm{W} \cdot \rho \cdot \mathrm{Cp} \cdot \Delta \mathrm{T}
\end{aligned}
$$

dimana :

$\mathrm{Q}=$ Daya reaktor $(\mathrm{kW})$

$\mathrm{W}=$ Laju alir volumetrik $\left(\mathrm{m}^{3} / \mathrm{s}\right)$

$\dot{\mathrm{m}}=$ Massa aliran pendingin $(\mathrm{kg} / \mathrm{s})$

$\mathrm{T}_{\text {in }}=$ Suhu keluar teras reaktor $\left({ }^{\circ} \mathrm{C}\right)$

$\mathrm{T}_{\text {out }}=$ Suhu masuk teras reaktor $\left({ }^{\circ} \mathrm{C}\right)$

$\mathrm{P}=$ massa jenis pendingin $\left(\mathrm{kg} / \mathrm{m}^{3}\right)$ 
$\mathrm{C}_{\mathrm{p}}=$ Panas spesifik pendingin $(\mathrm{kW}$. detik/kg ${ }^{\circ} \mathrm{C}$ )

$\Delta \mathrm{T}=$ Beda suhu keluaran dan masukan teras reaktor $\left({ }^{\circ} \mathrm{C}\right)$

Pada persamaan ini kehilangan panas dijalur sistem pendingin primer diabaikan.

Dengan mengukur besarnya laju alir sistem pendingin teras / pendingin primer (W), suhu masukan teras reaktor $\left(T_{\text {in }}\right)$ dan suhu keluaran teras reaktor $\left(T_{\text {out }}\right)$, serta memasukkannya dalam persamaan (2) di atas maka dapat dihitung besar daya reaktor yang dibangkitkan.Untuk $\Delta T$ yang kecil, harga $\mathrm{C}_{\mathrm{p}}$ dan $\rho$ dapat dianggap tetap, namun untuk mendapatkan ketelitian yang lebih baik maka harga $C_{p}$ dan $\rho$ harus dihitung / dikoreksi dengan Persamaan (3) dan (4) ${ }^{[3]}$.

$$
\begin{gathered}
\rho=1000\left(1,0029-1,5838 \cdot 10^{-4} \cdot T_{b}\right. \\
-2,847 \cdot 10^{-6} \cdot T_{b}{ }^{2} \\
C_{p}=4,167+0,05 \cdot e^{\left(-0,0734 T_{b}\right)} \\
+0,0031 \cdot e^{\left(0,0268 T_{b}\right)}
\end{gathered}
$$

dimana :

$\rho=$ massa jenis pendingin $\left(\mathrm{kg} / \mathrm{m}^{3}\right)$

$\mathrm{T}_{\mathrm{b}}=$ rerata suhu masu dan keluar teras reaktor $\left({ }^{\circ} \mathrm{C}\right)$

$\mathrm{C}_{\mathrm{p}}=$ Panas spesifik pendingin (kW. detik/kg ${ }^{\circ} \mathrm{C}$ )

Masing-masing parameter dapat diukur dari panel tegak di ruang kendali utama (RKU), JE01 CT001 (suhu masuk teras reaktor / $\mathrm{T}_{\text {in }}$ ) dan JE01 CT006 (suhu keluar teras reaktor / $\mathrm{T}_{\text {out }}$ ). Laju alir sistem pendingin primer dihitung dari jumlah laju alir yang terukur pada sensor JE01 CF811 / 821 / 831 dan KBE01 CF003.

Hasil pengukuran laju alir dan suhu tersebut dipergunakan untuk menghitung daya reaktor yang dibangkitkan di teras reaktor. Kemudian untuk mendapatkan hasil ketelitian yang baik dan benar dilakukan pengukuran faktor koreksi kalibrasi daya reaktor dengan cara mengoperasikan sistem pendingin primer dan sekunder serta sistem pendukungnya sampai perbedaan suhu masuk dan keluar teras mencapai harga stabil sebelum reaktor dioperasikan.

Persamaan (2) di atas digunakan untuk menghitung daya kalorimetri yang dipindahkan dari teras reaktor ke air pendingin primer, dengan terlebih dulu menghitung $\rho$ dan $C_{p}$ dengan Persamaan (3) dan (4). Hasil perhitungan ini hanya digunakan sebagai data pembanding.

Pehitungan kalibrasi daya reaktor dilakukan sesuai dengan SOP kalibrasi daya reaktor RSG-GAS Nomor : SOP 007.003/RN 00 01/RSG $2.2^{[4]}$.

\section{METODOLOGI}

Pada teras 96 sebelum reaktor RSG-GAS dioperasikan pada daya 30 MW terlebih dahulu reaktor dioperasikan secara rutin pada daya $15 \mathrm{MW}$ sesuai jadwal operasi reaktor yang telah ditentukan, dan sesuai dengan Instruksi Operasi, Persiapan Sarana Operasi, serta persyaratan teknis lainnya. Dimana sistem - sistem yang dioperasikan antara lain, sistem pendingin primer JE01 AP001 dan AP002, sistem pendingin sekunder PA01 dan PA02 AP001, 4 buah blower cooling tower PA01 AH001 / AH002 dan PA02 AH001 / AH002 (untuk operasi $30 \mathrm{MW}$ menggunakan 6 buah blower, dimana dua buah blower yaitu PA01 AH003 dan PA02 AH003 dioperasikan saat akan dilakukan manuver daya dari $15 \mathrm{MW}$ menuju 30 MW), sistem purifikasi air kolam reaktor KBE01 AP001 dan AP002, sistem purifikasi dan lapisan air hangat KBE02 AP001 beserta heatemya, dan sistem sistem pendukung lainnya ${ }^{[5]}$.

Analisis pengoperasian reaktor RSG-GAS pada teras 96 dengan daya maksimum $30 \mathrm{MW}$ dilakukan dengan 
metode kalibrasi daya reaktor dan kemudian membandingkan daya sebenarnya / aktual / hasil kalibrasi dengan daya yang dikehendaki.

Tata kerja yang dilakukan untuk mendapatkan data analisi pengoperasian reaktor RSG-GAS pada teras 96 dengan daya maksimum $30 \mathrm{MW}$, adalah :

1. Mencatat data yang diperlukan pada meja kendali berkenaan dengan daya dan parameter detektor. (daya reaktor awal $15 \mathrm{MW}$ ).

2. Mencatat data pada panel tegak yang diperlukan untuk perhitungan kalibrasi daya reaktor.

3. Setelah selesai mencatat data yang diperlukan, naikan daya reaktor (manuver daya) menuju daya yang dikehendaki.

4. Setelah reaktor kritis pada daya yang dikehendaki tunggu beberapa saat hingga dirasa parameter - parameter terkait telah berada pada kondisi stabil, kemudian catat parameter yang diperlukan seperti pada poin 1 dan 2 diatas.

5. Lakukan langkah poin $1 \mathrm{~s} / \mathrm{d} 4$ untuk tingkat daya lainnya sampai dengan daya maksimum $30 \mathrm{MW}$.

6. Setelah selesai mencatat data yang diperlukan sampai dengan daya maksimum $30 \mathrm{MW}$, padamkan reaktordengan aman dan selamat sesuai SOP yang berlaku.

\section{HASIL DAN PEMBAHASAN}

Berikut ini hasil pencatatan data dan hasil kalibrasi daya reaktor yang dilakukan pada pengoperasian reaktor RSG-GAS tanggal 15 Mei 2018 pada Teras 96.

Tabel 1. Pencatatan Data Pengoperasian Reaktor Sebelum Dilakukan Kalibrasi Daya.

\begin{tabular}{ccccc}
\hline \hline No & Jam & $\begin{array}{c}\text { Daya Reaktor } \\
\text { Yang Dikehendaki } \\
(\mathrm{MW})\end{array}$ & $\begin{array}{c}\text { Konversi JKT04 } \\
1 \times 10^{-10} \mathrm{~A} \\
(\text { Watt })\end{array}$ & $\begin{array}{c}\text { Harga Pengesetan } \\
\text { JKT04 } \\
(\mathrm{A})\end{array}$ \\
\hline \hline 1 & $08: 16$ & 15 & 30.963 & $0,48 \times 10^{-4}$ \\
\hline 2 & $10: 00$ & 15 & 30.963 & $0,48 \times 10^{-4}$ \\
\hline 3 & $13: 30$ & 18 & 30.963 & $0,57 \times 10^{-4}$ \\
\hline 4 & $13: 55$ & 20 & 30.963 & $0,64 \times 10^{-4}$ \\
\hline 5 & $14: 08$ & 25 & 30.963 & $0,80 \times 10^{-4}$ \\
\hline 6 & $14: 20$ & 27 & 30.963 & $0,89 \times 10^{-4}$ \\
\hline 7 & $15: 10$ & 30 & 30,350 & $0,99 \times 10^{-4}$ \\
\hline
\end{tabular}

Tabel 2. Data Setelah Dilakukan Kalibrasi Daya Reaktor

\begin{tabular}{|c|c|c|c|c|c|c|}
\hline No & Jam & $\begin{array}{c}\text { Daya } \\
\text { Reaktor } \\
\text { Yang } \\
\text { Dikehendaki } \\
(\mathrm{MW})\end{array}$ & $\begin{array}{l}\text { Daya Hasil } \\
\text { Perhitungan } \\
\text { Kalorimetri } \\
(\mathrm{MW})\end{array}$ & $\begin{array}{l}\text { Daya } \\
\text { Aktual / } \\
\text { Hasil } \\
\text { Kalibrasi } \\
\text { Daya } \\
\text { Reaktor } \\
\text { (MW) }\end{array}$ & $\begin{array}{c}\text { Konversi } \\
\text { JKT04 } \\
1 \times 10^{-10} \mathrm{~A} \\
\text { (Watt) } \\
\text { Setelah } \\
\text { Kalibrasi } \\
\text { Daya } \\
\text { Reaktor }\end{array}$ & $\begin{array}{c}\text { Harga } \\
\text { Pengesetan } \\
\text { JKT04 } \\
(\text { A) } \\
\text { Setelah } \\
\text { Kalibrasi } \\
\text { Daya } \\
\text { Reaktor }\end{array}$ \\
\hline 1 & 08:16 & 15 & 15,010 & 14,951 & 31.147 & $0,48 \times 10^{-4}$ \\
\hline 2 & $10: 00$ & 15 & 14,935 & 14,878 & 30,995 & $0,49 \times 10^{-4}$ \\
\hline 3 & $13: 30$ & 18 & 17,355 & 17,291 & 30,072 & $0,60 \times 10^{-4}$ \\
\hline
\end{tabular}




\begin{tabular}{ccccccc}
\hline \hline 4 & $13: 55$ & 20 & 19,002 & 19,311 & 30,174 & $0,66 \times 10^{-4}$ \\
\hline 5 & $14: 08$ & 25 & 23,471 & 23,415 & 29,260 & $0,85 \times 10^{-4}$ \\
\hline 6 & $14: 20$ & 27 & 26,178 & 26,120 & 29,340 & $0,92 \times 10^{-4}$ \\
\hline 7 & $15: 10$ & 30 & 30,073 & 30,040 & 30,040 & $0,99 \times 10^{-4}$ \\
\hline
\end{tabular}

Dari data pada tabel 1 di atas ditampilkan kondisi operasi reaktor dari daya $15 \mathrm{MW}$ sampai dengan daya maksimum $30 \mathrm{MW}$. Manuver daya dari daya $15 \mathrm{MW}$ menuju daya maksimum 30 MW dilakukan secara bertahap, hal ini dilakukan untuk memastikan sistem dan komponen reaktor serta parameter parameter yang ada berfungsi dengan baik. Pengesetan kanal pengukur daya JKT04 untuk daya 15 MW sampai dengan daya $27 \mathrm{MW}$ dilakukan dengan mengacu pada hasil konversi JKT04: $1 \times 10^{-10} \mathrm{~A}=30,963$ Watt, nilai konversi ini didapatkan dari hasil kalibrasi daya reaktor pada pengoperasian sebelumnya pada daya $15 \mathrm{MW}$. Sedangkan untuk daya $30 \mathrm{MW}$ dengan mempertimbangkan faktor keamanan dan keselamatan dalam pengoperasian reaktor serta melihat pada pengoperasian reaktor RSG-GAS dengan daya $30 \mathrm{MW}$ yang dilakukan sebelumnya pada teras 92 maka diputuskan untuk terlebih dulu dilakukan kalibrasi daya reaktor. Sehingga pengesetan kanal pengukur daya JKT04 sebesar $0,99 \times 10^{-4} \quad A$ menggunakan konversiJKT04 : $1 \times 10^{-10} A=30,350$ Watt (yang baru).

Pada tabel 2 disajikan data hasil kalibrasi daya reaktor. Pada daya $15 \mathrm{MW}$ didapatkan daya hasil kalibrasi sebesar 14,951 MW (4 buah blower colling tower beroperasi) dan sebesar 14,878 MW (6 buah blower colling tower beroperasi), dengan daya hasil perhitungan kalorimetri sebesar 15,010 MW (4 buah blower colling tower beroperasi) dan sebesar 14,935 MW (6 buah blower colling tower beroperasi).

Untuk daya $18 \mathrm{MW}$ didapatkan daya hasil kalibrasi sebesar 17,291 MW dengan daya hasil perhitungan kalorimetri sebesar 17,355 MW Kemudian pada daya 20 MW daya hasil kalibrasinya sebesar 19,311 dengan daya hasil perhitungan kalorimetri sebesar 19,002 MW. Sedangkan untuk daya $25 \mathrm{MW}$ dan $27 \mathrm{MW}$ daya hasil kalibrasinya masing - masing sebesar 23,415 MW dan 26,120 MW dengan daya hasil perhitungan kalorimetri sebesar 23,471 MW dan 26,178 MW. Dan pada daya maskimum $30 \mathrm{MW}$ didapatkan daya hasil kalibrasi sebesar 30,040 MW dengan daya hasil perhitungan kalorimetri sebesar 30,073 MW.

Antara daya hasil kalibrasi dengan daya yang dikehendaki untuk daya $15 \mathrm{MW}$ sampai dengan daya 27 MWterdapat perbedaan yang cukup besar antara $\pm 0,049 \mathrm{MW}$ sampai dengan \pm 1,585 MW. Perbedaan ini menjukan ada ketidaksesuaian pengoperasian pada rentang daya $15 \mathrm{MW}$ sampai dengan $27 \mathrm{MW}$, dimana hal ini dipengaruhi oleh besaran konversi JKT0 $4 \times 10^{-10}$ A yang digunakan sebagai acuan pengesetan kanal pengukur daya JKT04 (seperti pada table 1) menggunakan besaran konversi lama dan tidak dilakukan penyesuain pengesetan kanal pengukur daya JKT04 yang baru (harga pengesetan kanal pengukur daya JKT04 lama / pada tabel 1 cenderung berbeda dengan pengesetan kanal pengukur daya JKT04 baru / pada tabel 2).

Sedangkan untuk daya maksimum $30 \mathrm{MW}$ antara daya yang dikehendaki dengan daya hasil kalibrasi besarnya hampir sama, meskipun tetap masih ada sedikit perbedaan $( \pm 0,040$ MW). Sedikit perbedaan ini dianggap telah mewakili kesesuaian 
pengoperasian reaktor pada daya maksimum $30 \mathrm{MW}$, dimana pada daya ini telah lebih dulu dilakukan kalibrasi daya reaktor. Pengesetan kanal pengukur daya JKT04 yang lama (pada tabel 1) menggunakan besaran konversi JKT04 : $1 \times 10^{-10} A=30,350$ Watt (hasil kalibrasi daya reaktor terbaru), serta pengesetan kanal pengukur daya JKT04 yang lama sama dengan pengesetan kanal pengukur daya JKT04 yang baru.

\section{KESIMPULAN}

Pengoperasian reaktor RSGGAS teras 96 dari daya $15 \mathrm{MW}$ sampai dengan daya maksimum $30 \mathrm{MW}$ berjalan dengan aman dan selamat. Pengesetan kanal pengukur daya JKT04 untuk daya 15 MW sampai daya $27 \quad \mathrm{MW}$ menggunakan nilai konversi JKT04: $1 \times 10^{-10} \mathrm{~A}=30,963$ Watt (hasil kalibrasi daya pada operasi sebelumnya). Pengesetan kanal pengukur daya JKT04 untuk daya $30 \mathrm{MW}$ menggunakan nilai konversi JKT04 : $1 \times 10^{-10} A=30,350$ Watt (hasil kalibrasi daya terbaru).

Perbedaan antara daya aktual dengan daya yang dikehendaki pada rentang daya $15 \mathrm{MW}$ sampai daya 27 MW dianggap sebagai ketidaksesuaian pengoperasian karena pengesetan kanal

pengukur daya JKT04 masih menggunakan nilai konversi yang lama. Sedangkan untuk daya maksimum 30 MW meski tetap ada sedikit perbedaan antara daya aktual dengan daya yang dikehendaki dianggap telah mewakili atau terjadi kesesuaian pengoperasian, karena pengesetan kanal pengukur daya JKT04 telah menggunakan nilai konversi terbaru juga pengesetan kanal pengukur daya JKT04 sebelum dan setelah kalibrasi daya reaktor besarnya sama.

$$
\text { Dengan demikian dapat }
$$

dipastikan adanya kesesuaian pengoperasian reaktor RSG-GAS pada teras 96 dengan daya maksimum 30 MW.

\section{UCAPAN TERIMAKASIH}

Penulis mengucapkan terimakasih kepada banyak pihak yang telah membantu dalam berbagai hal sehingga akhirnya makalah ini dapat diselesaikan dengan baik dan sesuai harapan. Ucapan terimakasih ini terutama penulis sampaikan kepada:

1. Drs. R. Heru Umbara selaku Kepala PRSG yang telah memberikan dukungan dan motivasi kepada penulis.

2. Ir. Suwoto selaku Kepala Bidang Operasi Reaktor yang telah membimbing, memberikan arahan dan motivasi kepada penulis khususnya dalam penulisan makalah ini.

3. Rekan - rakan sejawat yang tidak dapat penulis sebutkan namanya satu - persatu yang turut membantu dan berpartisipasi sampai makalah ini selesai.

\section{DAFTAR PUSTAKA}

1. Sukiyanto. 2017. Ketidaksesuaian Pengoperasian Reaktor RSG-GAS Pada Teras 92 Dengan Daya Maksimum $30 \mathrm{MW}$. Prosiding SENPATEN 2017.

2. PRSG - BATAN. 2011. Laporan Analisis Keselamatan Operasi Reaktor Serbaguna G.A Siwabessy BATAN Revisi 10.1. Serpong : PRSG - BATAN.

3. Isnaini, Darwis. 1995. Tabel Konversi Daya Reaktor PRSG BATAN. Jakarta : BATAN.

4. PRSG - BATAN. 2016. Standar Operasional Prosedur Kalibrasi Daya Reaktor RSG-GAS Nomor : SOP 007.003/RN 00 01/RSG 2.2. Serpong : PRSG - BATAN. 
5. PRSG - BATAN. 2018. Instruksi Operasi No :

RSG.OR.IO.96/03/2018. Serpong :

PRSG - BATAN. 